\title{
First record of the harlequin ladybird, Harmonia axyridis (Coleoptera: Coccinellidae) in the Caucasus
}

\author{
Natalia A. BELYAKOVA ${ }^{1}$ and Sergey Ya. REZNIK ${ }^{2 *}$ \\ ${ }^{1}$ All-Russian Institute of Plant Protection, Russian Academy of Agricultural Sciences, Pushkin, 196608, St. Petersburg, Russia \\ ${ }^{2}$ Zoological Institute, Russian Academy of Sciences, 199034, St. Petersburg, Russia; e-mail: reznik1952@mail.ru
}

Key words. Coleoptera, Coccinellidae, Harmonia axyridis, invasions, Caucasus, Russia, photoperiod

\begin{abstract}
This is the first record of the harlequin ladybird Harmonia axyridis (Pallas) (Coleoptera: Coccinellidae) occurring in the Caucasus (Sochi region of Krasnodar territory, Russia). All the adults collected in the field there and reared from collected eggs, larvae and pupae, and their progeny were H. axyridis f. succinea, which is the most common morph in natural populations in SouthEastern Asia and the Russian Far East as well as in invasive populations in the Americas and Europe. In contrast in Western Siberia f. axyridis predominates and this indicates that an occasional introduction from the closest native range in Siberia cannot be considered as the source of the Caucasian population. It is known that populations of $H$. axyridis can also differ in their photoperiodic responses. The results of earlier experiments on $H$. axyridis, which originated from the Russian Far East, indicate that the threshold day lengths for the acceleration of preimaginal development and deceleration of reproductive maturation were 13-14 h, while for the invasive populations of this species in Europe these two thresholds are approximately $12 \mathrm{~h}$. In the population studied, the thresholds for both of these photoperiodic responses were also approximately $12 \mathrm{~h}$. Thus, it is concluded that the population of $H$. axyridis studied is a further eastward continuation of the invasion of this species in Europe.
\end{abstract}

\section{INTRODUCTION}

The history of the invasion by Harmonia axyridis (Pallas) (Coleoptera: Coccinellidae) is thoroughly described in several review papers (Brown et al., 2008; Koch \& Galvan, 2008; Roy \& Wajnberg, 2008; Lombaert et al., 2010; Brown et al., 2011). At the beginning of the last century, this predaceous coccinellid was introduced into the USA from South-Eastern Asia and since then it has been successfully used in many countries for the biological control of insect pests, mostly in greenhouses. However, about 20 years ago the harlequin ladybird invaded natural ecosystems. At present, H. axyridis occurs in almost 40 countries in Europe, North and South America, and Africa and now is considered to be an invasive species, which is having a negative effect on native aphidophagous insects (Koch \& Galvan, 2008; Roy \& Wajnberg, 2008).

Harmonia axyridis is native to South-Western Siberia and Kazakhstan. As is obvious from the most recent distribution maps for this species (Poutsma et al., 2008; Lombaert et al., 2010; Brown et al., 2011) there is a gap between the eastern and western parts of the current geographical range of this species in the Caucasus and southern parts of European Russia.

During summer 2012 we received a personal communication from T. Mogilevich (Zelenograd, Moscow province), which kindly informed us that he had found several beetles very similar to the harlequin ladybird in the Sochi region. To check this, a special collection trip was organized in autumn 2012. Eggs, larvae, pupae and adults of $H$. axyridis were collected and a laboratory population was established. Generally speaking, this population could have three sources: (1) European invasive populations, (2) Far Eastern native populations, from where $H$. axyridis has been repeatedly introduced into the south of European Russia and, in particular, the Sochi region (Bugaeva et al., 2011), and (3) the most western part of native range of $H$. axyridis in South-Western Siberia and Kazakhstan (Poutsma et al.,
2008; Lombaert et al., 2010; Brown et al., 2011). Note that in this case the distance is not a deciding factor as Sochi is the biggest and most popular resort in Russia (http://www.routesonline. com/airports/8475/sochi-international-airport/) with very extensive traffic with other parts of Russia and a relatively high probability of an unintentional introduction.

The present paper contains a short description of the invasive population and the results of laboratory studies with an emphasis on a comparison of our results with those for other populations of $H$. axyridis. In particular, we investigated the effect of day length on the rate of development and maturation because our recent studies indicate that European and Far Eastern populations of $H$. axyridis differ in their photoperiodic responses (Reznik \& Belyakova, 2013) and that the pattern in the photoperiodic response is stable over several tens of generations when reared under constant diapause-averting conditions in the laboratory (Reznik \& Vaghina, 2011).

\section{MATERIAL AND METHODS}

Eggs, larvae, pupae and adults of $H$. axyridis were collected in the Sochi region (Krasnodar territory, Russia) from 27 September to 3 October 2012. Three infestations of this species were found: (1) in the City of Sochi $\left(43^{\circ} 35^{\prime} 32^{\prime \prime} \mathrm{N}, 39^{\circ} 43^{\prime} 36^{\prime \prime} \mathrm{E}\right)$ on Catalpa speciosa Warder ex Engelm; (2) in Loo $\left(43^{\circ} 42^{\prime} 12^{\prime \prime} \mathrm{N}, 39^{\circ} 35^{\prime} 11^{\prime \prime} \mathrm{E}\right)$ on Ambrosia artemisiifolia L.; and (3) in Lazarevskoe $\left(43^{\circ} 53^{\prime} 43^{\prime \prime} \mathrm{N}, 39^{\circ} 21^{\prime} 15^{\prime \prime} \mathrm{E}\right)$ on Hibiscus syriacus L. and Tilia sp.

In total, 120 individuals (mostly larvae and pupae) and 7 batches of eggs were collected and transported to the Laboratory of Biological Control, All-Russian Institute of Plant Protection. In the laboratory, larvae were kept in plastic containers (diameter $15 \mathrm{~cm}$, height $10 \mathrm{~cm}$ ), adults were kept in pairs in plastic Petri dishes (diameter: $9 \mathrm{~cm}$, height: $1.5 \mathrm{~cm}$ ). Insects were kept at $24-26^{\circ} \mathrm{C}$ and under an $18 \mathrm{~L}: 6 \mathrm{D}$ photoperiod and

\footnotetext{
* Corresponding author.
} 


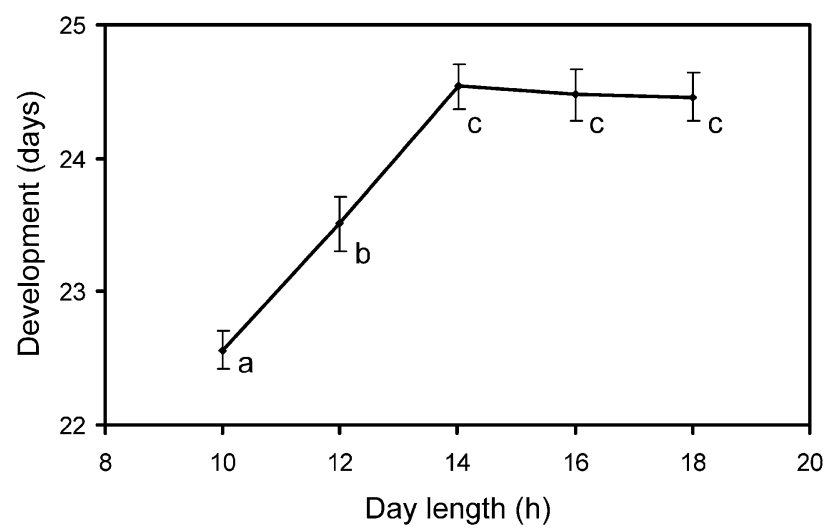

Fig. 1. Influence of photoperiod on the total duration of larval and pupal development in Harmonia axyridis. Means and SEM are shown. Values marked by different letters are significantly different $(\mathrm{p}<0.05$, the Tukey HSD test $)$.

were fed on the wheat aphid Schizaphis graminum Rond. reared on wheat seedlings. Colour morphs of collected and emerging adults were identified (Dobzhansky, 1933; Tan, 1946). Then, a laboratory population (the progeny of the collected individuals) was reared under the same conditions.

For the eco-physiological experiments, the eggs laid by females of the $1^{\text {st }}$ generation of the laboratory population were transported to the Laboratory of Experimental Entomology, Zoological Institute. The experiments were conducted in a thermostatically controlled room at $20^{\circ} \mathrm{C}$. To start the test, seven cohorts of recently emerged first instar larvae were randomly placed in chambers with photoperiods of $10,12,14,16$ and 18 h. Cohorts were separated by an interval of 2-3 days; for each photoperiod, two chambers located on opposite sides of the thermostatic room were used. Larvae and adults were fed on the green peach aphid, Myzus persicae (Sulz.) reared on broad bean, Vicia faba L. (about 100 aphids were provided daily on bean seedlings). The larvae were kept individually in plastic Petri dishes. Adult emergence was recorded daily 4-6 h after the lights switched on. The emerged adults were sexed and kept in pairs under the same photoperiodic conditions as during their preimaginal development (males from the main laboratory population were used if necessary). To determine the preoviposition period, each Petri dish was checked for eggs daily, also 4-6 h after the lights switched on. Thus, the total duration of larval and pupal development of all individuals and the time of reproductive maturation of females were recorded. Our previous studies (Reznik \& Vaghina, 2011, 2013) showed that more than $90 \%$ of the females of $H$. axyridis fed on M. persicae at $20^{\circ} \mathrm{C}$ under long day conditions started to lay eggs within 20 days of emergence. Thus, a female that did not lay eggs during this period was recorded as undergoing delayed maturation. Forty days after emergence (when most females had started to lay eggs) the experiment was terminated.

Development of 56-61 individuals and maturation of 27-30 females were recorded for each of the 5 photoperiods. The duration of preimaginal development was analyzed using ANOVA and Tukey HSD test. The percentage of females that started to lay eggs within or after 20 days were compared using chi-square tests. All the calculations were made using SYSTAT.

\section{RESULTS}

\section{Morph frequency}

All the adults collected in the Sochi region and reared from collected eggs, larvae and pupae $(\mathrm{n}=108)$ were $H$. axyridis $\mathrm{f}$.

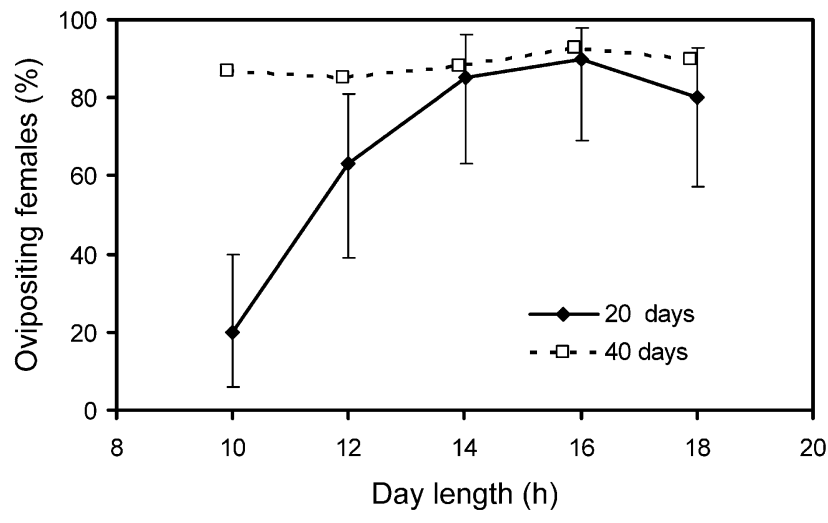

Fig. 2. Influence of photoperiod on the percentage of Harmonia axyridis females that started to lay eggs within and after 20 days after emergence. For those that oviposited within 20 days the $95 \%$ confidence intervals are indicated.

succinea. Adults of the first generation of the progeny of females that were fertilized in the field $(n=172)$ were also $f$. succinea suggesting that the population studied was practically monomorphic.

\section{Effects of photoperiod on development and maturation}

The preliminary analysis of the results (two-way ANOVA, $n$ $=289$ ) showed that the duration of development was not dependent on which side of the thermostatic room the rearing chamber was situated $(\mathrm{df}=1, \mathrm{~F}=0.166, \mathrm{P}=0.684)$ and the interaction of the "chamber factor" with photoperiod was also not significant $(\mathrm{df}=4, \mathrm{~F}=1.470, \mathrm{P}=0.211)$. The difference among cohorts was statistically significant $(\mathrm{df}=6, \mathrm{~F}=3.782, \mathrm{P}$ $=0.001$ ) although the effect of this "cohort factor" was much weaker than that of photoperiod $(\mathrm{df}=4, \mathrm{~F}=14.743, \mathrm{P}<0.001)$. The interaction of the above two factors was not significant (df $=24, \mathrm{~F}=0.941, \mathrm{P}=0.546$ ), which means that the pattern of the photoperiodic response was the same in all cohorts. Chi-square test showed that the percentage of females that started to lay eggs within and after 20 days, respectively, also were not significantly different in the different chambers with the same photoperiod and among cohorts (both $\mathrm{P}>0.1$ ). Thus, the pooled data for all cohorts and chambers were used in subsequent analyses.

Two-way ANOVA of the pooled data $(n=289)$ showed that the total duration of the larval and pupal development was significantly dependent on photoperiod ( $\mathrm{df}=4, \mathrm{~F}=22.9, \mathrm{P}<$ 0.001 ). Although males developed slightly faster than females, this difference was not statistically significant $(\mathrm{df}=1, \mathrm{~F}=2.8, \mathrm{p}$ $=0.095$ ). The interaction of the two factors was also not significant $(\mathrm{df}=4, \mathrm{~F}=1.1, \mathrm{p}=0.354)$ and thus the data for males and females were combined. As seen in Fig. 1, the development of H. axyridis reared in chambers in which the day-length was $10 \mathrm{~h}$ was about $10 \%$ faster than that of those that experienced a $14 \mathrm{~h}$ day-length, while the differences between photoperiods of 14 , 16 and $18 \mathrm{~h}$ were not significant. The threshold of this quantitative photoperiodic response, i.e. day length corresponding to the mean of the maximum and minimum durations of development (Zaslavski, 1988) is roughly estimated as $12 \mathrm{~h}$ (Fig. 1).

As seen in Fig. 2, the percentage of females that started to lay eggs during the first 20 days of the experiment was significantly $\left(\mathrm{n}=145, \mathrm{df}=4, \chi^{2}=44.5, \mathrm{p}<0.001\right)$ dependent on the photoperiod: at a 10-h-long day the percentage of the females that oviposited was a third of that at 14-, 16- and 18-h-long days. At the end of the experiment, however, $80-90 \%$ of females laid eggs independently of day length $\left(\chi^{2}=1.3, \mathrm{df}=4, \mathrm{p}=0.856\right)$. 


\section{DISCUSSION}

The form composition of the population studied is very similar to that at the same latitude in Northern Italy, where most individuals are of f. succinea and only $2.48 \%$ of $\mathrm{f}$. spectabilis (Burgio et al., 2008). In Croatia, only f. succinea are recorded in 10 of the 21 local populations inspected, although some of the other populations included a high proportion of $\mathrm{f}$. spectabilis and / or f. conspicua. (Stanković et al., 2011). Monomorphy is typical for early small invasive populations, which have often originated from a single or few individuals. On average, $70-90 \%$ of the individuals in invasive populations of $H$. axyridis in Europe are f. succinea (Brown et al., 2008). In the Russian Far East (from where H. axyridis was repeatedly introduced into European Russia) and in South-Eastern Asia (from where, directly or via USA, European invasive populations originated) f. succinea also comprise about $90 \%$ of the adults in natural populations. In South-Western Siberia, in contrast, f. axyridis predominates (Dobzhansky, 1933; Kholin, 1990; Blehman, 2007; Seo et al., 2008; Belyakova, 2013). This striking difference in the percentages of morphs suggests that an occasional introduction from the closest native range in Siberia and Kazakhstan can not be considered as the source of the Caucasian population. To choose between European invasive and Far Eastern native populations based on this criterion is practically impossible, although this can be done using molecular genetic analysis (Lombaert et al., 2010; Brown et al., 2011).

Diapause-inducing short days can accelerate the development of the stages preceding diapause, thus increasing the period of time for preparing for the adverse period (Zaslavski, 1988; Saunders et al., 2002). In particular, this effect is documented for H. axyridis (Iperti \& Bertrand, 2001; Berkvens et al., 2008; Reznik \& Vaghina, 2011, 2013; Hodek, 2012) and our new results agree well with those of these studies. It is also known that when females of $H$. axyridis are provided with their "essential" food (aphids) under short day conditions they will start ovipositing after varying periods of time. However, under short day conditions the preoviposition period is longer and, in combination with the decreasing temperature and shortage of prey that occur in nature in autumn, this delay in maturation can turn into a long-term winter diapause (Berkvens et al., 2008; Reznik \& Vaghina, 2011, 2013; Hodek, 2012).

In the context of the present study, it is noteworthy that the experiments conducted with the laboratory strain of $H$. axyridis that originated from the Russian Far East (Reznik \& Vaghina, 2011) show that the threshold day lengths for the acceleration of preimaginal development and deceleration of reproductive maturation are approximately $13-14 \mathrm{~h}$. Similar experiments with the laboratory population that originated from Europe (Czech Republic) show that these two thresholds are approximately 12 h (Reznik \& Belyakova, 2013). Note that the photoperiodic responses of the 3 strains compared (the Far Eastern, the European, and Caucasian) were recorded in the same laboratory using the same food, the same equipment and the same methods. As for the possible effects of artificial selection caused by mass rearing, the laboratory stock of the "Caucasian strain" had only recently been established and that of the "European strain" had only completed less than 10 generations in the laboratory before their response to photoperiod was determined (Reznik \& Belyakova, 2013) and the photoperiodic threshold of the "Far Eastern strain" remained stable over 25-30 generations when it was reared under stable diapause-averting conditions (Reznik \& Vaghina, 2011). Thus, it is most likely that the reason for the difference in thresholds is that although Southern Europe is at approximately the same latitude as the Russian Far East, the latter is characterized by colder autumns and conse- quently there is an advantage in entering diapause earlier there than in Southern Europe (Reznik \& Vaghina, 2011). Similar inter- and intra-specific variations in the thresholds of the photoperiodic responses are recorded for many insects (Zaslavski, 1988; Saunders et al., 2002). The present study revealed that the threshold day length of the Caucasian population is equal to or somewhat shorter than that of the European population. If the population studied had originated from the individuals introduced from the Far East one would expect the threshold day length to be longer. Hence, this comparison of the patterns in the photoperiodic responses of the different strains indicates that the invasive population of $H$. axyridis discovered in Sochi region came from the west rather than the east.

Harmonia axyridis was first introduced from the Russian Far East into Georgia more than 80 years ago. Since then, it has been repeatedly introduced into the south of European Russia, but these introductions never resulted in establishment (Poutsma et al., 2008; Brown et al., 2008, 2011; Bugaeva et al., 2011; Lombaert et al., 2010), although there are sporadic reports of adults, which are probably the close descendants of individuals that escaped from rearing facilities (Merkviladze \& Kvavadze, 2001; Ukrainskii \& Shapovalov, 2010; Orlova-Bienkowskaja, 2013). Thus, it is very unlikely that the rapid invasion by $H$. axyridis of Southeastern Europe and the first discovery of this beetle in the Caucasus are coincidental. Rather, it is a new manifestation of the "bridgehead effect", which most probably has been an important determinant of the invasiveness of the harlequin ladybird world-wide (Lombaert et al., 2010; Brown et al., 2011). However, it is also possible that the Caucasian populations include hybrids between invasive European individuals and those introduced from the Far East for use in biocontrol. Such hybridization can play an important role in promoting an invasion (Turgeon et al., 2011). To finally clarify this question large-scale field collections and molecular genetic analyses of the collected material are planned.

ACKNOWLEDGEMENTS. We thank M.Yu. Dolgovskaya, A.A. Khodzhash, T.Yu. Moskaleva, A.N. Ovchinnikov, L.S. Ramenskaya and E.N. Tukhtina for their excellent technical assistance. We are grateful to the two anonymous reviewers for their valuable comments and corrections. This work was partly supported by the Program of the Presidium of the Russian Academy of Sciences "Living Nature: Current State and the Problems of Development".

\section{REFERENCES}

Belyakova N.A. 2013: Polymorphism of the lady beetle Harmonia axyridis (Coleoptera, Coccinellidae) in the Baikal population. - Entomol. Rev. 93: 50-55.

Berkvens N., Bonte J., Berkvens D., Tirry L. \& De Clerce P. 2008: Influence of diet and photoperiod on development and reproduction of European populations of Harmonia axyridis (Pallas) (Coleoptera: Coccinellidae). - BioControl 53: 211-221.

Blehman A.V. 2007: Variability of pronotum patterns in ladybird beetle Harmonia axyridis Pallas (Coleoptera, Coccinellidae). - Ekol. Genet. 5: 25-36 [in Russian].

Brown P.M.J., Adriaens T., Bathon H., Cuppen J., Goldarazena A., Hagg T., Kenis M., Klausnitzer B.E.M., Kovar I., Loomans A.J.M., Majerus M.E.N., Nedved O., Pedersen J., Rabitsch W., Roy H.E., Ternols V., Zakharov I.A. \& Roy D.B. 2008: Harmonia axyridis in Europe: spread and distribution of a non-native coccinellid. - BioControl 53: 5-21.

Brown P.M.J., Thomas C.E., Lombaert E., Jefrries D.L., Estoup A. \& Handley L.J.L. 2011: The global spread of Har- 
monia axyridis (Coleoptera: Coccinellidae): distribution, dispersal and routes of invasion. - BioControl 56: 623-641.

Bugaeva L.N., Ignatieva T.N., Novikov Yu.P. \& Kashutina E.V. 2011: The problem of protection of vegetable plants in organic farming. - Inf. Bull. EPS IOBC 42: 32-35 [in Russian].

Burgio G., Santi F., Lanzoni A., Masetti A., De Luigi V., Melandri M., Reggiani A., Ricci C., Loomans A.J.M. \& MAINI S. 2008: Harmonia axyridis recordings in northern Italy. - Bull. Insectol. 61: 361-364.

DoBZHANSKY Tн. 1933: Geographical variation in lady-beetles. - Am. Nat. 67: 97-126.

Hodek I. 2012: Diapause / Dormancy. In Hodek I., van Emden H.F. \& Honěk A. (eds): Ecology and Behaviour of the Ladybird Beetles (Coccinellidae). Wiley-Blackwell, Chichester, pp. $275-342$.

IPERTI G. \& BÉRTRAND E. 2001: Hibernation of Harmonia axyridis (Coleoptera: Coccinellidae) in South-Eastern France. Acta Soc. Zool. Bohem. 65: 207-210.

KHoLIN S.K. 1990: Stability of the genetical polymorphism in color of Harmonia axyridis Pall. (Coccinellidae, Coleoptera) in Maritime province, USSR. — Genetika 26: 2207-2214 [in Russian].

Koch R.L. \& GaLvan T.L. 2008: Bad side of a good beetle: the North American experience with Harmonia axyridis. - BioControl 53: 23-35.

Lombaert E., Guillemaud T., Cornuet J.M., Malausa T., FACON B. \& Estoup A. 2010: Bridgehead effect in the worldwide invasion of the biocontrol harlequin ladybird. - PLoS ONE 5(3): e9743.

Merkviladze M.Sh. \& Kvavadze E.Sh. 2001: List of ladybirds (Coleoptera, Coccinellidae) of Georgia. — Proc. Inst. Zool. (Tbilisi) 21: 149-155.

Orlova-BienKowsKaJa M.JA. 2013: The dangerous invasive harlequin ladybird Harmonia axyridis (Pallas, 1773) (Coleoptera, Coccinellidae) in European Russia. - Russ. J. Biol. Invas. 1: 75-82.

Poutsma J., Loomans A.J.M., Aukema B. \& Heijerman T. 2008: Predicting the potential geographical distribution of the harlequin ladybird, Harmonia axyridis, using the CLIMEX model. - BioControl 53: 103-125.
Reznik S.Ya. \& Belyakova N.A. 2013: Photoperiodic effects on development and maturation in the invasive European population of Harmonia axyridis (Pallas) (Coleoptera, Coccinellidae). - Proc. Russ. Entomol. Soc. 84 (in press) [in Russian].

Reznik S.Ya. \& Vaghina N.P. 2011: Photoperiodic control of development and reproduction in Harmonia axyridis (Coleoptera: Coccinellidae). — Eur. J. Entomol. 108: 385-390.

REZNIK S.YA. \& VAGHINA N.P. 2013: Effects of photoperiod and diet on diapause tendency, maturation and fecundity in Harmonia axyridis (Coleoptera: Coccinellidae). - J. Appl. Entomol. 137: 452-461.

Roy H. \& Wajnberg E. 2008: From biological control to invasion: the ladybird Harmonia axyridis as a model species. BioControl 53: 1-4.

Saunders D.S., Steel C.G.H., Vafopoulou X. \& Lewis R.D. 2002: Insect Clocks. Elsevier, Amsterdam, 560 pp.

Seo M.J., Kim G.H. \& Youn Y.N. 2008: Differences in biological and behavioural characteristics of Harmonia axyridis (Coleoptera: Coccinellidae) according to colour patterns of elytra. - J. Appl. Entomol. 132: 239-247.

Stanković V.M., Koren T. \& Stanković I. 2011: The Harlequin ladybird continues to invade southeastern Europe. - Biol. Invas. 13: 1711-1716.

TAN C.C. 1946: Mosaic dominance in the inheritance of color patterns in the lady-bird beetle, Harmonia axyridis (Pallas). - Genetics 31: 195-210.

Turgeon J., Tayeh A., Facon B., Lombaert E., De Clerce P., Berkvens N., Lundgren J.G. \& Estoup A. 2011: Experimental evidence for the phenotypic impact of admixture between wild and biocontrol Asian ladybird Harmonia axyridis involved in the European invasion. - J. Evol. Biol. 24: 1044-1052.

UkRAINSKII A.S. \& Shapovalov M.I. 2010: Coccinellidae - Lady birds. In Zamotailov A.S. \& Nikitskii N.B. (eds): Beetles (Insecta, Coleoptera) of Adygea Republic. Adygea State University Publishing House, Maykop, pp. 199-201 [in Russian].

ZaslavsKi V.A. 1988: Insect Development: Photoperiodic and Temperature Control. Springer, New York, 187 pp.

Received April 8, 2013; revised and accepted May 29, 2013 